ISSN 1676-3742

\title{
Ciência moderna, religião e os novos ateístas ${ }^{1}$
}

\author{
Wilmar do Valle Barbosa \\ Roney de Seixas Andrade
}

\section{Resumo}

Este artigo analisa o discurso de alguns neo-ateístas norte-americanos, a partir de um ponto de vista que considera o neo-ateísmo como um movimento atuante em uma "guerra de cultura" e que emerge no início deste milênio como resposta ao ressurgimento político e cultural do fundamentalismo cristão nos Estados Unidos, a partir de 1970. Os marcos teórico-conceituais aqui utilizados nos permitem uma perpesctiva apropriada para o estudo deste discurso, bem como das propostas ético-políticas deste movimento. Os autores aqui analisados entendem que a postura neo-ateísta é crítica e renovadora. Em nossa avaliação, todavia, esta postura, apesar de se diferenciar dos ateísmos tradicionais, constitui uma expressão tardia do que entendemos ser o "fundamentalismo secularista”.

Palavras-chave: Ciência, Religião, Política, Neo-ateísmo.

\footnotetext{
${ }^{1}$ Comunicação apresentada em 02 de outubro de 2012 no VII Congresso Latino-Americano sobre Ciência e Religião realizada na PUC-Rio e co-organizado pelo Ian Ramsey Centre for Science and Religion, Univerty of Oxford, e pela PUC-Rio.
} 


\begin{abstract}
This paper analyses the discourse of some north-American new atheists, from a point of view that considers the New Atheism as a movement acting in a "culture wars" and that emerges at the beginning of this millennium as a response to political and culture resurgence of Christian Fundamentalism in the United States since 1970. The theoretical and conceptual frameworks used here allow us an appropriate perspective for the study of this discourse, as well as the ethical and policy proposals of this movement. The authors analyzed here understand that the New Atheist stance is critical and refreshing. In our view, however, this stance despite differentiate themselves from traditional atheism, is a late expression of what we understand to be the "secularist fundamentalism".
\end{abstract}

Key-words: Science, Religion, Policy, New atheism.

\title{
Introdução
}

Na última década observamos, particularmente nos Estados Unidos, ações do movimento conhecido como neo-ateísmo com vistas a deslegitimar toda forma de alusão à religião e, sobretudo, a toda e qualquer concepção que atribua valor epistêmico à ideia de sobrenatureza. A partir dos atentados de 11 de setembro de 2001, diversos intelectuais norte-americanos publicaram livros best-sellers, afirmando que a religião, sobretudo na forma dos fundamentalismos dos três monoteísmos, constitui ameaça à sobrevivência das nossas sociedades e que a ciência constitui o único meio válido e possível de conhecimento.

Diferentemente dos ateísmos anteriores, este movimento destaca-se pela afirmação do ateísmo como cosmovisão plausível e coerente para nossa era e por considerar que toda forma de fé ou crença em qualquer tipo de deidade é algo negativo em si mesmo, devendo, por conseguinte ser eliminada do contexto social e educacional. Outra característica deste movimento, que contrasta com ateísmos passados, é a sua ligação intrínseca com o discurso científico, em especial com a teoria evolucionista darwinista. Consequentemente, os neo-ateístas reconhecem no darwinismo um poderoso fundamento da concepção materialista de existência.

Como não poderia deixar de ser, um fator importante a ser considerado na avaliação deste movimento é o contexto em que ele surge. Em nosso entendimento, o neo-ateísmo é uma resposta a um momento político-cultural mais 
geral, ou seja, ao retorno do religioso no espaço público de sociedades seculares ocidentais. Porém, mais especificamente, consideramos que o neo-ateísmo nos EUA constitui uma resposta ao ressurgimento político e cultural do fundamentalismo cristão neste país, algo que vem se dando ao longo dos últimos 40 anos. De fato, movimentos com um viés reconhecidamente fundamentalista tais como a Christian Coalition e a Moral Majority articularam, a partir da década de 1970, uma ideologia de matriz teológico-política e uma base social que se encontram na origem da atual e expressiva presença da chamada nova direita cristã, predominantemente evangélica, no âmbito do Partido Republicano. No nosso entendimento, este "republicanismo evangélico" é um dos vetores fortes que vem promovendo, desde então e paulatinamente, uma clivagem no âmbito das elites político-culturais norte-americana, instaurando, assim, um novo tipo de conflito no espaço público dos EUA. Por ser, desta feita, conflito basicamente cultural, o eixo dos desacordos políticos sobre itens socioculturais da agenda pública pode ser reconduzido a questões relativas a diferentes concepções de autoridade moral, tidas, desta feita, como irreconciliáveis por seus respectivos defensores. ${ }^{2}$ Neste contexto emerge o neo-ateísmo.

\section{O Discurso Neo-Ateísta}

Podemos afirmar que o movimento neo-ateísta tornou-se conhecido da opinião pública norte-americana sobretudo a partir da publicação de quatro polêmicos best-sellers: The End of Faith (2004), escrito pelo neurocientista Sam Harris; Breaking the Spell (2006), do filósofo Daniel Dennett; The God Delusion (2006), elaborado pelo reconhecido biólogo evolucionista Richard Dawkins; God is not Great (2007), de autoria do jornalista político Christopher Hitchens. A partir dessas publicações o discurso neo-ateísta tem se propagado, ganhando visibilidade e notoriedade, sobretudo no espaço público dos Estados Unidos, através de jornais, revistas, artigos, web sites, talk-shows televisivos e radiofônicos e, ainda, através da publicação de outros livros. Após analisarmos os livros em pauta, percebemos a existência de pelo menos quatro eixos centrais que animam e alinham o discurso neo-ateísta. O primeiro é a deslegitimação do viés religioso de compreensão acerca dos fins últimos da existência; o segundo é o reconhecimento da ciência como única e exclusiva forma universalmente válida de conhecimento; o terceiro é a defesa da concepção materialista de

${ }^{2}$ Sobre estas questões cf. HUNTER, James. Culture wars: the struggle to define America. New York: Basic Books, 1991, p. 128. 
existência; o quarto e último eixo é o reconhecimento do ateísmo como única cosmovisão plausível e coerente para nossa era.

No que diz respeito ao primeiro eixo do discurso neo-ateísta, ou seja, a deslegitimação do viés religioso de compreensão, um dos principais alvos é justamente, como se poderia esperar, a experiência religiosa, sobretudo aquelas vivenciadas no contexto dos três grandes monoteísmos. Todos os principais autores neo-ateístas dirigem suas críticas à presença das diversas formas de religiões no espaço público, social e cultural. Mas não apenas isto. Uma vez que são da opinião que toda forma de fé ou de crença em qualquer tipo de deidade é negativa em si mesma, culminam por propor uma verdadeira erradicação do religioso e das instituições religiosas. Segundo Arthur Bradley e Andrew Tate, estudiosos do neo-ateísmo, o que une substantivamente os quatro atores neoateísta citados é a convicção de que a fé religiosa não é apenas irracional, mas é também imoral e perigosa. ${ }^{3}$

De fato, podemos verificar a radicalidade desta convicção ao nos confrontarmos com a opinião do mais zeloso neo-ateísta, Richard Dawkins. Em sua obra The God Delusion, este cientista afirma que "o Deus do Antigo Testamento talvez seja o personagem mais desagradável da ficção: ciumento, e com orgulho; controlador mesquinho, injusto e intransigente; genocida étnico e vingativo, sedento de sangue; perseguidor misógino, homofóbico, racista, infanticida, filicida, pestilento, megalomaníaco, sadomasoquista, malévolo". ${ }^{4}$ Em outra passagem desta mesma obra, Dawkins, fazendo menção a John Lennon, descreve sua própria noção de como o mundo seria melhor sem a presença da religião:

Imagine, junto com John Lennon, um mundo sem religião. Imagine o mundo sem ataques suicidas, sem o 11/9, sem o 7/7 londrino, sem as Cruzadas, sem caça às bruxas, sem a Conspiração da Pólvora, sem a partição dos territórios indígenas, sem as guerras entre israelenses e palestinos, sem os massacres de sérvios/croatas/muçulmanos, sem a perseguição de judeus vistos como "assassinos de Cristo", sem "os problemas" da Irlanda do Norte, sem "assassinatos em nome da honra", sem evangélicos televisivos de terno brilhante e cabelo bufante tirando dinheiro dos ingênuos ("Deus quer que você doe até doer"). ${ }^{5}$

\footnotetext{
${ }^{3}$ BRADLEY, A. \& TATE, A. The New Atheist Novel. Philosophy, Fiction and Polemic after 9/11. London/New York: Continuum International Publishing Group, 2010, p. 3.

${ }^{4}$ DAWKINS, Richard. Deus, um delírio. São Paulo: Companhia das Letras, 2007, p. 43.

${ }^{5}$ Ibid, p. 18.
} 
Este mesmo tipo de crítica direta, ou indireta, à suposta imoralidade constitutiva das religiões pode também ser observado entre os demais neo-ateístas citados. Para Christopher Hitchens, por exemplo, a religião, como sugere o subtítulo de seu livro, "envenena tudo". ${ }^{6}$ Sam Harris, por sua vez, considera que "a fé religiosa representa um uso mal-empregado e intransigente do poder de nossas mentes que forma um tipo de singularidade cultural perversa - um ponto de escape além do qual o discurso racional se torna impossível". ' Como seria de se esperar, Harris acredita que os mais monstruosos crimes contra a humanidade foram invariavelmente inspirados por uma fé sem evidências. ${ }^{8}$

Assim sendo, através desses e de outros criticismos os atores neo-ateístas procuram deslegitimar a presença das religiões ou das crenças religiosas no espaço público $e$ privado. Consequentemente, preconizam a substituição do discurso religioso e a religião stricto sensu, nas explicações globais e últimas da vida e do universo, pelo conhecimento fornecido pela ciência, que neste caso, convenhamos, funcionaria como uma verdadeira metafísica. Isto nos leva a considerar o próximo eixo do discurso neo-ateísta, ou seja, a afirmação da ciência como única fonte de conhecimentos universalmente válidos sobre a natureza, os homens e o cosmos.

Segundo R. Albert Mohler Jr., um dos pontos altos do movimento neo-ateísta seria justamente sua ligação intrínseca com o discurso científico, em especial com a teoria evolucionista darwinista. ${ }^{9}$ Nesta mesma direção o antropólogo social Flávio Gordon reconhece que os autores neo-ateístas concebem a ciência num sentido puramente materialista e, dessa forma, entendem que "toda a realidade é realidade material e apenas a ciência estaria equipada intelectualmente para oferecer informação sobre ela". ${ }^{10}$ Por isso mesmo, Dawkins, discordando do NOMA (Non-overlapping Magisteria) de Stephen Jay Gould,

\footnotetext{
${ }^{6}$ HITCHENS, Christopher. Deus não é Grande: como a religião envenena tudo. Rio de Janeiro: Ediouro, 2007.

${ }^{7}$ HARRIS, Sam. A Morte da Fé: religião, terror e o futuro da razão. São Paulo: Companhia das Letras, 2009, p. 28.

${ }^{8}$ Ibid, p. 85.

${ }^{9}$ MOHLER Jr., R. Albert. Ateísmo remix: um confronto cristão aos novos ateístas. São José dos Campos: Ed. Fiel, 2009, p. 17. Em relação à ligação do discurso neo-ateísta com a teoria evolucionista darwinista, Richard Dawkins chega mesmo a declarar que esta teoria é a única teoria conhecida capaz de resolver, em princípio, o mistério de nossa existência. Ver: DAWKINS, Richard. The Blind Watchmaker: Why the Evidence of Evolution Reveals a Universe without Design, New York: W. W. Norton, 1986, p. xviii.

${ }^{10}$ GORDON, Flávio. A Cidade dos Brights: Religião, Política e Ciência no Movimento Neo-Ateísta. Rio de Janeiro: UFRJ, 2010, p. 319.
} 
chega mesmo a questionar a possível validade das respostas elaboradas pelo discurso religioso para qualquer questão que a ciência não possa eventualmente responder. ${ }^{11}$ Em sua opinião, "se a ciência não pode responder a determinadas questões últimas, o que faz alguém pensar que a religião pode?". ${ }^{12}$

Outro fato interessante a ser observado no discurso neo-ateísta é a estrutura argumentativa desenvolvida a partir da oposição entre ciência e religião ou entre ciência e Bíblia. No âmbito desta argumentação, a ciência recebe $a$ priori uma espécie de "supremacia epistêmica" na compreensão do real, ou na definição da verdade, enquanto que a religião, devido a sua suposta inconsistência, deveria ser de partida objeto de uma científica desconstrução.

Em sua obra Breaking the Spell, Daniel Dennett concebe a religião como objeto da avaliação e julgamento da ciência ao tratá-la como um fenômeno natural. No seu entendimento, a "religião é natural no sentido de ser oposto ao sobrenatural, o que significa dizer que a religião é um fenômeno humano composto de eventos, organismos, objetos, estruturas, padrões, e outros, que obedece às leis da física ou da biologia e, portanto, não está relacionada a milagres". ${ }^{13}$ Uma vez que a religião é concebida como um fenômeno regido por leis naturais ela está, consequentemente, sujeita às análises científicas. Todavia, Dennett apressa-se a esclarece que não está "sugerindo que a ciência deveria tentar fazer o que a religião faz, mas que ela deveria estudar, cientificamente, o que a religião faz" ${ }^{14}$ Interessante notar, porém, que a dinâmica religiosa aqui, é percebida como possível objeto da física e da biologia, o que significa supor que fenômenos culturais possuem fundamentos que são extra sociais, que são biológicos, por exemplo.

Outro exemplo dessa lógica argumentativa acerca do caráter irreconciliável da oposição entre ciência e religião pode ser observado no livro Letter to $a$ Christian Nation, no qual seu autor, Sam Harris, deixa claro esse caráter e a superioridade das explicações científicas em face das religiosas. No seu parecer,

\footnotetext{
${ }^{11}$ O termo "NOMA" foi cunhado por Stephen Jay Gould em sua obra Rocks of Ages (1999), editado no Brasil sob o título Pilares do Tempo: ciência e religião na plenitude da vida. Rio de Janeiro: Rocco, 2002. De acordo com Gould, ciência e religião seriam dois magistérios distintos e que não se sobrepõem.

${ }^{12}$ DAWKINS, Richard. Deus, um delírio, p. 68.

13 "I might mean that religion is natural as opposed to supernatural, that it is a human phenomenon composed of events, organisms, objects, structures, patterns, and the like that obey the laws of physics or biology, and hence do not involve miracles". DENNETT, Daniel. Breaking the Spell: Religion as a Natural Phenomenon. New York: Viking, 2006, p. 25.

14 "I am not suggesting that science should try to do what religion does, but that it should study, scientifically, what religion does". DENNETT, Daniel. Breaking the Spell, pp. 30-31.
} 
A escolha que temos pela frente é simples: podemos ter uma conversa do século XXI acerca da moral e do bem-estar humano - uma converas na qual recorremos a todas as descobertas científicas e argumentos filosóficos acumulados nos últimos 2 mil anos de discurso humano - ou então podemos nos confinar a uma conversa do século I, tal como preservada na Bíblia. Por que alguém haveria de querer adotar a segunda opção? ${ }^{15}$

Com esta declaração, Harris pretende validar sua tese segundo a qual a definição da moralidade e do bem-estar social deve estar baseada no conhecimento científico (o único válido) e não nos discursos religiosos. De fato, em vários outros trechos de sua obra, Harris segue contestando a validade da Bíblia como um fundamento seguro e válido das verdades morais. Para ele,

As questões morais são questões de felicidade e sofrimento. É por isso eu e você não temos obrigações morais em relação às pedras. Até onde nossas ações podem afetar a experiência de outras criaturas, de maneira positiva ou negativa, as questões de moral se aplicam. A ideia de que a Bíblia é o guia perfeito para a moralidade é simplesmente espantoso, em vista do conteúdo do livro. [...] Você acredita que, se a Bíblia não for aceita como a palavra de Deus, não pode haver um padrão universal de moralidade. Mas podemos facilmente pensar em fontes objetivas de ordem moral que não requerem a existência de um Deus legislador. [...] Se existem leis psicológicas que governam o bem-estar humano, conhecer essas leis nos proporcionaria uma base duradoura para uma moralidade objetiva. ${ }^{16}$

Esta compreensão de que o conhecimento fornecido pela ciência, contrastando com a religião, seria o único fundamento universalmente válido da autoridade moral, leva-nos a considerar outro eixo presente no discurso neo-ateísta: a concepção materialista de existência.

Segundo John Lennox, os autores neo-ateístas sugerem que "o universo com sua profusão de belas galáxias e dotado de sua sutil complexidade biológica é produto de forças irracionais agindo sobre a matéria e a energia de forma desordenada". ${ }^{17}$ De fato, ao discorrer especificamente sobre o ateísmo mesmo, Richard Dawkins declara que um ateu é alguém que...

\footnotetext{
${ }^{15}$ HARRIS, Sam. Carta a uma Nação Cristã. São Paulo: Companhia das Letras, 2007, p. 55.

${ }^{16}$ Ibid, p. 25 e 35.

17 "Are we and the universe with its profusion of galactic beauty and subtle biological complexity nothing but the products of irrational forces acting on mindless matter and energy in an unguided way, as the so-called New Atheists, led by Richard Dawkins, suggest?". Ver: LENNOX, John. God's Undertaker: Has Science Buried God? Lion Hudson, Oxford, 2007, p.1.
} 
[...] acredita que não há nada além do mundo natural e físico, nenhuma inteligência sobrenatural criativa vagando por trás do universo observável, que não existe uma alma que sobrevive ao corpo e que não existem milagres - exceto no sentido de fenômenos naturais que não são ainda compreendidos. Se houver alguma coisa que pareça estar além do mundo natural, conforme o entendemos hoje, esperamos no fim ser capazes de entendê-la e adotá-la dentro da natureza. Assim como acontece sempre que desvendamos um arco-íris, ele não será menos maravilhoso por causa disso. ${ }^{18}$

Essa afirmação é típica do que alguns chamam de "identidade bright". Em sua web site, criada em 2003, o biólogo Paul Geisert e a educadora Mynga Furtrell empregaram o termo bright ("brilhante", "luminoso") para designar os adeptos da visão de mundo ateísta ou, como preferem dizer, naturalística. De acordo com a definição apresentada nesse site, um bright "é uma pessoa que possui uma visão de mundo naturalística. Uma "visão de mundo bright" é livre de elementos sobrenaturais e místicos. A ética e as ações de um bright são baseadas em uma visão de mundo naturalística". ${ }^{19}$ Assim sendo, argumentam os autores do site, se sua visão de mundo é livre de deidades, forças e entidades sobrenaturais ou místicas, então você é, por definição, um bright! Várias pessoas que se reconheceram nesta visão assumiram a "identidade bright", dentre as quais dois dos principais expoentes do neo-ateísmo, Daniel Dennett e Richard Dawkins.

Uma vez que no discurso neo-ateísta a religião e todo teísmo oferecem um grande "perigo", eles devem ser necessariamente eliminados do contexto social, cultural e educacional. A ciência, por sua vez, estaria equipada para ocupar o lugar da religião stricto sensu enquanto explicação metafísica, digamos, acerca dos fins últimos da existência, e enquanto fonte das verdades morais. Uma vez que o universo e a vida não seriam resultantes de um ato criativo de alguma divina inteligência, mas o produto de forças aleatórias, de conflitos, de repulsão e atração cristalizadas no processo de seleção natural, os atores neo-ateístas concluem que única cosmologia coerente e plausível seria mesmo o ateísmo, enquanto que a concepção materialista de existência seria a única capaz de nos permitir uma existência melhor.

\footnotetext{
${ }^{18}$ DAWKINS, Richard. Deus, um delírio, p. 28.

19 "A bright is a person who has a naturalistic worldview. A bright's worldview is free of supernatural and mystical elements. The ethics and actions of a bright are based on a naturalistic worldview". Disponivel em: <http://www.the-brights.net>. Acesso em: 11 set. 2012.
} 
No prefácio de seu livro The God Delusion, Richard Dawkins desenvolve algumas proposições que nos remetem ao último dos quatro principais eixos de nossa análise do discurso neo-ateísta, isto é, a crença segundo a qual o ateísmo é uma cosmovisão plausível e coerente para nossa época. ${ }^{20}$

Como apontado por alguns analistas e críticos do movimento neoateísta, o darwinismo ou a síntese neodarwinista, a despeito de seus elementos científicos, tem servido como um poderoso unificador da concepção materialista de existência no âmbito deste movimento. De fato, assim como muitos criacionistas e fundamentalistas, os neo-ateístas também reconhecem a incompatibilidade entre a teoria de Darwin e as narrativas bíblicas da criação, pois na avaliação dessas correntes de pensamento, a visão darwinista de mundo, ao excluir Deus de todo o processo, conduz necessariamente ao ateísmo. Assim sendo, o darwinismo tem servido, paradoxalmente, tanto como razão dos contra-discursos criacionista e fundamentalista, para não falar da teoria do design inteligente, quanto como legitimação epistemológica da concepção materialista de existência defendida pelo movimento neo-ateísta. Nas palavras do próprio Richard Dawkins, em seu livro The Blind Watchmaker, "Darwin tornou possível ser um ateu intelectualmente realizado". ${ }^{21}$

Conforme observado por Flávio Gordon, o darwinismo representa uma síntese exemplar, conectando a história e a natureza numa teoria científica unificada. Citando o neo-darwinista alemão Ernst Mayr, para quem "Darwin introduziu historicidade na ciência", Gordon afirma ser esse o motivo pelo qual "Darwin excitou a imaginação tanto dos cientistas naturais quanto dos cientistas históricos, e o darwinismo, inicialmente uma teoria científica sobre a evolução das espécies, passou a ser uma das ideologias mais poderosas do século $\mathrm{XX}$, a

${ }^{20}$ De fato, neste prefácio Dawkins declara que, caso seu livro funcione da forma com que ele espera, "os leitores religiosos que o abrirem serão ateus quando o terminarem". Além disso, sua intenção com este livro é conscientizar seus leitores, "conscientizar para o fato de que ser ateu é uma aspiração realista, e uma aspiração corajosa e esplêndida. É possível ser um ateu feliz, equilibrado, ético e intelectualmente realizado" DAWKINS, Richard. Deus, um delírio, p. 18. Evidentemente, nenhuma pessoa de bom senso pode negar a última frase desta citação. $\mathrm{O}$ católico Pierre Bayle, já havia sugerido, em 1682, no seu livro Pensées diverses sur le comète que ser ateu não era tão imoral como acreditavam seus contemporâneos cristãos, propondo, assim, uma distinção entre moral e moral católica. Todavia, é sempre bom lembrar que ser uma pessoa religiosamente orientada não impede a ninguém ser tão realizado quanto o ateu de Dakwins! Sobre Bayle, cf. NEIMAN, Susan. O mal no pensamento moderno. Uma história alternativa da filosofia. Rio de Janeiro: Difel, 2003.

21 "Darwin made it possible to be an intellectually fulfilled atheist". DAWKINS, Richard. The Blind Watchmaker, p. 6. 
ponto de alguns, mais ou menos explicitamente, como é o caso dos neo-ateístas, sugerirem ser A Origem das Espécies a versão secular da Bíblia".22

$\mathrm{Na}$ avaliação de R. Albert Mohler Jr., hoje não apenas existem alternativas para a cosmovisão bíblica, mas essas alternativas são também apresentadas como "superiores". De fato, se o ato de "não crer" era minoritário, senão raro, até poucos séculos atrás - visto que era considerado "excêntrico, imoral e perigoso" - no atual momento, é o teísmo que passa a ser considerado "perigoso", tal como constata Mohler Jr. E os neo-ateista pensam assim porque, segundo este autor, no entendimento deles "as pessoas que creem em Deus são pessoas perigosas, que fazem coisas arriscadas. Elas são um tóxico letal em meio à nossa cultura.".23

Na coleção do que considera ser "leituras essenciais para nonbelievers", seu organizador, Christopher Hitchens, inclui o texto The Philosophy of Atheism, de Emma Goldman, escrito no início do século passado. Neste ensaio sua autora já apresentava a concepção-mestra que anima a imaginação teórica dos atuais promotores do neo-ateísmo, a saber: a concepção segundo a qual, diferentemente do teísmo ( $\mathrm{e}$, consequentemente, da religião) que funciona como um dos instrumentos de controle e dominação, o ateísmo conduz as pessoas à liberdade. Para Emma Goldman nesta perspectiva que opõe controle-dominação versus liberdade-autonomia

A filosofia do ateísmo expressa a expansão e desenvolvimento da mente humana. A filosofia do teísmo, se é que podemos chamá-la de filosofia, é estática e fixa. [...] A filosofia do ateísmo representa uma concepção de vida sem qualquer outro mundo metafísico ou qualquer regulador divino. [...] O triunfo da filosofia do ateísmo é a liberdade do homem do pesadelo dos deuses; o que significa a dissolução dos fantasmas do além. [...] A filosofia do ateísmo tem suas raízes na terra, nesta vida; seu objetivo é a emancipação da raça humana de todos os deuses, sejam eles Judaicos, Cristãos, Maometanos, Budistas, Hinduístas, ou não. ${ }^{24}$

${ }^{22}$ GORDON, Flávio. A Cidade dos Brights, pp. 86-87. MAYRS, Ernst. Darwin's Influence on Modern Thought, Scientific American (julho de 2000).

${ }^{23}$ MOHLER Jr., R. Albert. Ateísmo remix, p. 39.

24 "The philosophy of Atheism expresses the expansion and growth of the human mind. The philosophy of theism, if we can call it philosophy, is static and fixed. [...] The philosophy of Atheism represents a concept of life without any metaphysical Beyond or Divine Regulator. [...] The triumph of the philosophy of Atheism is to free man from the nightmare of gods; it means the dissolution of the phantoms of the beyond. [...] The philosophy of Atheism has its root in the earth, in this life; its aim is the emancipation of the human race from all God-heads, be they 
Discordando radicalmente da posição dos atores neo-ateístas, William Dembski afirma que "a mentalidade de nosso tempo já não segue ancorada no materialismo ateu que durante tanto tempo dominou a vida intelectual do Ocidente. Esta cosmovisão atéia, supostamente apoiada pela ciência, constituiu o principal impedimento, ao menos no Ocidente, para se levar a sério o cristianismo. Agora que se questiona o próprio materialismo ateu, o cristianismo volta a estar sobre o tapete". ${ }^{25}$ Além disso, Dembski, observa que a recente onda de livros escritos pelos autores neo-ateístas careceria de sentido se o cristianismo, bem como o teísmo em geral, não houvesse recuperado sua relevância cultural. De fato, estes considerações de Dembski nos levam a confrontar os temas relacionados ao contexto do surgimento do movimento neo-ateísta, ou seja, o debate em torno do suposto "retorno do religioso" nas sociedades ocidentais e das ações do fundamentalismo cristão nos EUA nas últimas décadas.

\section{O Contexto da Emergência do Movimento Neo-Ateísta}

Muito embora os principais livros dos autores denominados de neo-ateístas tenham sido publicados após os atentados terroristas de 11 de setembro de 2001 e, mesmo considerando esse evento como um marco geral para o desenvolvimento e notoriedade do discurso neo-ateísta, sobretudo nos EUA, entendemos, com já indicamos acima, que o movimento neo-ateísta tem raízes mais profundas. ${ }^{26}$ Somos do parecer que ele emerge como resposta a um momento político e cultural mais geral, ou seja, ao assim chamado "retorno do religioso" no espaço público de sociedades seculares ocidentais. Mais pontualmente, como uma resposta ao ressurgimento político-cultural do fundamentalismo cristão e sua reinserção no espaço público nos EUA a partir de 1970 anos, quando se assiste à emergência de importantes movimentos e organizações políticas cristãs tais como a Coalizão Cristã e a Maioria Moral. Tais movimentos representaram os primeiros passos dados a nível nacional, em direção a atual presença cultural e político-partidária da nova direita cristã nos EUA, após o processo Scopes, ocorrido em 1925. ${ }^{27}$

Judaic, Christian, Mohammedan, Buddhistic, Brahministic, or what not". GOLDMAN, Emma. The Philosphy of Atheism. In: HITCHENS, Christopher. The Portable Atheist: essential readings for the nonbeliever. Philadelphia: Da Capo Press, 2007, p. 132-133.

${ }^{25}$ DEMBSKI, WIilliam A. The End of Christianity. Tennesse: B\&H Publishing Group, 2010, p. 2.

${ }^{26}$ BRADLEY, Arthur \& TATE, Andrew. The New Atheist Novel, p. 3

${ }^{27}$ O processo Scopes, ou caso Scopes, foi um julgamento ocorrido em julho de 1925 no Estado norte-americano do Tennessee - onde o ensino da teoria evolucionista da origem do homem 
Em seus textos os autores neo-ateístas afirmam reiteradamente que religião estaria novamente exercendo uma enorme influência na esfera pública, sobretudo no âmbito da sociedade norte-americana. Segundo o argumento dos neo-ateístas, bem como de alguns outros pensadores que se alinham com o secularismo, estaria em curso uma retomada, um retorno da influência da religião na definição das políticas públicas relacionada a diferentes agendas, tais como educação, pesquisa científica, entretenimento, família, dentre outras, que colocaria em risco os ideais democráticos desta sociedade.

A jornalista Michelle Goldberg, por exemplo, tem sugerido que este "retorno do religioso", é, na verdade, manifestação de uma espécie de "nacionalismo cristão" norte-americano, ou seja, da "convicção de que o verdadeiro cristianismo deve governar todos os aspectos da vida pública e privada, e que tudo - governo, história, ciência, cultura e relacionamentos - deve ser entendido de acordo com os ditames contidos nas Escrituras". Assim sendo, em sua opinião, muito embora os Estados Unidos não sejam nem jamais foram uma teocracia no sentido tradicional do termo, deve-se reconhecer que este "nacionalismo cristão" possui um viés fortemente teocrático. ${ }^{28}$

Por sua vez, Ben Stahlberg, ao avaliar esta "América Teocrática" e analisar o argumento de Goldberg, considera que neste ambiente dito nacionalistaonde há posições sobre qualquer tipo de questão, desde casamento gay até taxas de imposto de renda, publicamente reiteradas e consideradas religiosamente corretas - aqueles que optam por não considerar criticamente tais "posições bíblicas corretas" são frequentemente hostilizados e rotulados de "anti-americanos". ${ }^{29}$

Sam Harris é ainda mais incisivo em sua crítica à influência da religião na política. Segundo esse autor, "o grau em que as ideias religiosas ainda determinam as políticas governamentais - especialmente nos Estados Unidos - repre-

fora proibido pelo Butler Act aprovado em 21/03/1925 - no qual um professor de biologia chamado John Scopes teve que se defender, em juízo, da acusação por parte de fundamentalistas de que ensinara a seus alunos a teoria da evolução das espécies de Charles Darwin. Sobre o processo Scopes, cf. EUVÉ, François. Darwin et le christianisme, vrais et faux débats. Paris: Buchet Chastel, 2009, p. 95. Ver também: JOHNSON, Phillip E. Darwin no banco dos réus. São Paulo: Cultura Cristã, 2008, p. 16ss. Sobre o Butler Act, cf. <http://creationwiki.org/ Butler_Act>. Acesso em: 12 nov. 2012.

${ }^{28}$ GOLDBERG, M. Kingdom Coming: The Rise of Christian Nationalism. New York: W. W. Norton, 2006, p. 5.

${ }^{29}$ STAHLBERG, Ben. Theocratic America? Christianity and the Structure of Political Discourse. In: ROBBINS, J. and MAGEE, N. The Sleeping Giant has Awoken: The new politics of religion in the United States. New York: The Continuum International Publishing Group, 2008, p. 99. 
sentam um grave perigo a todos". Para sustentar seu argumento, ele apresenta alguns exemplos, amplamente divulgados, os quais sugerem que, de fato, ideias religiosas têm determinado diversas políticas públicas. Dentre outros, o autor menciona a interpretação acerca dos conflitos médio-orientais feita por Ronald Reagan através das lentes da profecia bíblica. Segundo Harris, "por muitos anos a política norte-americana no Oriente Médio foi moldada, em última instância, pelos interesses que os cristãos fundamentalistas têm no futuro de um Estado Judeu”. Assim sendo, continua este neo-ateista, "estas intromissões da escatologia no âmbito das políticas modernas sugerem que os perigos que a fé religiosa oferece dificilmente podem ser exagerados". A conclusão de Harris, portanto, é que a política norte-america para o oriente médio (quando não a política externa como um todo) vem sendo fortemente influenciada pela agenda política da christian right. ${ }^{30}$

Em relação à influência da religião no âmbito do ensino das ciências e das instituições escolares, o movimento neo-ateísta direciona suas críticas principalmente ao atual movimento do Design Inteligente. Em seu livro God, the Devil and Darwin: A critique of intelligent design theory publicado em $2004 \mathrm{e}$ prefaciado por Richard Dawkins, Niall Shanks, que também se alinha com o discurso neo-ateísta, considera os ataques à ciência promovidos pelos proponentes da Teoria do Design Inteligente (TDI) e pelo criacionismo em geral, como fragmentos da larga rejeição do secularismo que permearia as sociedades democráticas ocidentais e os EUA. ${ }^{31}$ De acordo com Shanks,

Uma guerra de culturas está sendo travada nos Estados Unidos por extremistas religiosos que esperam ajustar o relógio da ciência de volta à época medieval. $\mathrm{O}$ ataque atual visa, sobretudo, instituições educacionais e o ensino de ciências em particular. Contudo, há nessa pequena ação, uma mais larga rejeição do secular, do racional e dos democráticos ideais do iluminismo sobre o qual os Estados Unidos foram fundados. A principal arma nessa guerra é uma versão do criacionismo científico conhecida

\footnotetext{
30 "The degree to which religious ideas still determine government policies - especially those of the United States - presents a grave danger to everyone. [...] These intrusions of eschatology into modern politics suggest that the dangers of religious faith can scarcely be overstated". HARRIS, Sam. The End of Faith: religion, terror and future of reason. New York: W.W. Notyon \& Company, 2004, p. 153-154. [A Morte da Fé, p. 167-168].

${ }^{31}$ SHANKS, Niall. God, the Devil and Darwin: A critique of intelligent design theory. Oxford University Press, 2004, p. xi.
} 
como teoria do design inteligente. ${ }^{32}$

De acordo com Niall Shanks, como podemos perceber, a TDI nada mais é do que uma versão de criacionismo não menos perigosa para a ciência, a política, a educação e para a própria sociedade em geral. No seu entender essa teoria não constitui apenas um vetor de uma estratégia que visa reintroduzir a religião nos currículos escolares. Na realidade ela seria um componente de uma estratégia política bem mais ampla, cujo objetivo seria desafiar e deslegitimar as fundações do Estado moderno e secular. ${ }^{33}$

Essas críticas neo-ateístas sobre a influência da religião no âmbito das sociedades seculares, leva-nos a considerar uma questão importante, em nosso entendimento: a aparente contradição entre dois discursos conflitantes. De um lado, o discurso do fundamentalismo protestante norte-americano, no qual é reforçada sistematicamente a constatação da perda da influência do cristianismo no âmbito da esfera pública daquele país. Por outro lado, o discurso neo-ateísta - que se configura como um contra-discurso ao fundamentalismo - no qual é expresso o sentimento da perda da relevância dos ideais secularistas diante do suposto retorno da influência religiosa no espaço público das sociedades seculares. Diante dessas diferentes percepções sobre o lugar e o papel da religião no espaço público podemos nos perguntar: estamos vivendo um momento pós-cristão, momento de perda de eficácia organizadora da religião sobre a vida da sociedade, como parecem sugerir os fundamentalistas, ou estamos em um momento pós-secular, momento de potencialização desta mesma eficácia, como sugerem os atores ligados ao movimento neo-ateísta? Mas, quem sabe, estamos vivenciando a coexistência desses dois momentos?

Segundo o filósofo francês Marcel Gauchet, o mundo contemporâneo assiste a duas dinâmicas simultâneas e co-constitutivas: um processo em andamento de "saída da religião, compreendida como saída da capacidade do religioso em estruturar a política e a sociedade" como um todo, e a um processo de "permanência do religioso na ordem da convicção última dos indivíduos, observando nesse terreno um amplo espectro de variações, segundo as experiências históricas e nacionais muito amplas". ${ }^{34}$

Entretanto, na avaliação deste pensador esta permanência da fé com suas

\footnotetext{
${ }^{32}$ SHANKS, Niall. God, the Devil and Darwin: A critique of intelligent design theory, $\mathrm{p} . \mathrm{xi}$. ${ }^{33}$ SHANKS, Niall. God, the Devil and Darwin: A critique of intelligent design theory, p. 7. ${ }^{34}$ FERRY, Luc \& GAUCHET, Marcel, Le religieux aprés la religion, Paris: Ed. Grasset et Fasquelle, 2004, p. 55 (ed. brasileira: Depois da Religião: O que será do homem depois que a religião deixar de ditar a lei? Rio de Janeiro: Difel, 2008, p. 41).
} 
revivescências periódicas, não sugere de modo algum, um retorno da religião enquanto $a$ instituição estruturante da totalidade social, da vida das sociedades. Mesmo diante de fenômenos mais pontuais, como o caso dos fundamentalismos islâmicos a partir a década de 1970, com o Irã, ou no caso do fundamentalismo nos Estados Unidos, país "que oferece um exemplo único da coexistência de uma sociedade funcionando segundo uma lógica secular e, em muitos aspectos, mais materialista do que qualquer outro lugar e de um povo religioso", tais retornos não indicam uma recomposição da organização das sociedades com base na eficácia estruturante das religiões. Não o indicam mesmo ali onde "as igrejas tornaram-se depositárias da identidade nacional devido a motivos históricos", como na Irlanda, Polônia ou Grécia. ${ }^{35}$ Por outro lado, a saída da religião "não significa desaparição de qualquer experiência do tipo religioso". Muito ao contrário, "significa desprendimento da organização da realidade coletiva segundo o ponto de vista do outro, porém desprendimento que faz aparecer a experiência subjetiva do outro como um resto antropológico talvez irredutível".36

A levar em consideração as análises de Marcel Gauchet, podemos perceber que os EUA estão presenciando a coexistência de dois momentos que operam simultaneamente. De um lado, um momento "pós-cristão", que pode ser visto como uma etapa de "saída da religião", ou seja, momento de grande inflexão da capacidade organizadora do cristianismo sobre a totalidade da vida social norte-americana. Por outro, uma permanência e até mesmo uma intensificação das crenças religiosas, as quais muito embora possuam um papel social importante como acontece neste país, não constituem mais a única reserva de sentido e de fundamentos para os indivíduos e para o estar-junto coletivo. Desde o momento em que a religião deixa efetivamente de constituir a fonte das fontes organizadoras das instituições sociopolíticas e culturais e de operar como matriz da lei e como fundamento exclusivo da autoridade moral, passamos a vivenciar um definitivo deslocamento do ponto de aplicação da religião em nossas sociedades, não obstante o atual "retorno do religioso", como afirmam uns, ou o "reencantamento do mundo", como desejam outros. Assim sendo, ela se torna apenas mais uma reserva de sentido dentre outras a fundamentar as convicções últimas dos indivíduos. É importante ressaltar

${ }^{35}$ GAUCHET, Marcel. Un Monde Désenchanté? Paris: Les Éditions de l'Atelier/Éditions Ouvrières, 2004, pp. 11-13.

${ }^{36}$ GAUCHET, Marcel. Le désenchantement du monde. Une histoire politique de la religion, Paris: Editions Gallimar, 1985, p. 233. 
que processo de clivagem no âmbito das elites político-culturais e religiosas norte-americanas que estamos a presenciar decorre justamente deste deslocamento do ponto de aplicação histórico da religião. Como veremos a seguir, este processo tem gerado um novo tipo de conflito no espaço público dos EUA, o qual, por sua vez, tem dado às controvérsias entre neo-ateístas, conservadores e fundamentalistas cristãos a dimensão de uma guerra de cultura.

\section{O Neo-Ateísmo e a "Guerra de Cultura"}

Em seu livro Culture War: the struggle to define America, publicado em 1991, o norte-americano James Hunter, sociólogo da cultura, desenvolveu o argumento segundo o qual "Os EUA estão em meio a uma guerra de cultura que tem e continuará tendo reverberações não apenas em relação às políticas públicas, mas sobre a vida ordinária dos americanos, estejam onde estiverem". ${ }^{37}$ Hunter nos faz saber que ele mesmo define guerra ou "conflito cultural muito simplesmente como hostilidade social e política enraizada em diferentes sistemas de entendimento moral. A finalidade às quais tendem estas hostilidades é a dominação de um ethos cultural e moral sobre todos os outros". ${ }^{38}$

De acordo com a opinião desse sociólogo, esta guerra ou conflito de cultura em curso traz consigo um novo realinhamento dos antigos conflitos culturais próprios da história norte-americana e que envolveram protestantes, católicos, judeus e mórmons ao longo do século XIX e início do séc. XX. Segundo Hunter, esses antigos conflitos, que tinham um caráter teológico ou eclesiástico, foram em grande medida removidos da experiência americana contemporânea, devido justamente à expansão da tolerância cultural, do pluralismo religioso e das orientações seculares. Entretanto, vale destacar que os princípios e ideais que fundavam as opções dos diferentes atores desses conflitos, possuíam um caráter de ultimatum. Por isso mesmo, não eram considerados simples disposição do espírito que poderia ser modificada ou revogada. Eram considerados verdades reveladas e irrevogáveis, exigências últimas que constituíam fonte de identidade, propósito e comunhão para as pessoas que viviam em consonância com eles. ${ }^{39}$

\footnotetext{
37 "America is in the midst of a culture war that has and will continue to have reverberations not only within public policy but within the lives of ordinary Americans everywhere". HUNTER, James. Culture wars, p. 34.

${ }^{38}$ HUNTER, James. Culture wars, p. 42.

39 "I define cultural conflict very simply as political and social hostility rooted in different systems of moral understanding. The end to which these hostilities tend is the domination of one cultural and moral ethos over all others". HUNTER, James. Culture Wars, p. 42.
} 
A novidade agora, neste novo realinhamento de conflitos, é que as divisões não refletem mais desacordos teológicos ou eclesiásticos, ou seja, questões de doutrina, de observância dos rituais e organização religiosa. Segundo Hunter, os desacordos tradicionais entre as referidas denominações religiosas foram basicamente resolvidos, no início do século XX, através de acordos forjados com base nos simbolismos e no imaginário do teísmo bíblico. Todavia, esses acordos tornaram-se inócuos, paulatinamente.

Neste novo contexto ao qual estamos nos referindo, os conflitos e divisões, bem como suas expressões culturais e políticas, não decorrem mais das diferenças de caráter teológico e eclesiástico, como já dissemos. São agora resultantes de diferentes visões de mundo e concepções acerca do fundamento da autoridade moral. ${ }^{40}$ De acordo com Hunter, tais divisões e conflitos não se dão mais, basicamente, "em torno de questões específicas de doutrinas ou de estilos de práticas e organizações religiosas, mas em torno de nossa mais fundamental e estimada compreensão acerca do como ordenar nossas próprias vidas e nosso vida conjunta nesta sociedade. Nossas ideias mais fundamentais acerca de quem somos como americanos estão agora em desacordo.". ${ }^{41}$

No contexto deste novo realinhamento, o cerne da discordância encontra-se na diferença radical acerca da compreensão e tratamento de itens socioculturais da agenda pública tais como aborto, educação das e proteção às crianças, financiamento público para artes, saúde pública, ações afirmativas, homossexualismo, valores na educação pública, multiculturalismo, seguridade social, dentre outros. Não há como negar que tais itens, que se referem ao domínio do próprio corpo, à procriação, ao diferente, às opções sexuais, à liberdade de escolha, à universalização de direitos, dentre outras questões, implicam em valores que devem orientar nossos juízos e escolhas morais. "Morais" porque esses juízos e escolhas implicam em determinar e aceitar estes ou aqueles valores a partir das quais estabeleceremos justificativa ou razões que, por sua vez, regularão nossa conduta.

São justamente as diferentes e opostas visões de mundo, bem como as diferentes e também opostas razões que fundam os juízos, as escolhas e as

\footnotetext{
${ }^{40}$ Com o termo "autoridade moral", Hunter designa "as bases pelas quais as pessoas determinam se algo é bom ou mau, certo ou errado, aceitável ou não aceitável, e assim por diante”. HUNTER, James. Culture Wars, p. 42.

41 "They no longer revolve around specific doctrinal issues or styles of religious practice and organization but around our most fundamental and cherished assumptions about how to order our lives - our own lives and our lives together in this society. Our most fundamental ideas about who we are as Americans are now at odds". HUNTER, James. Culture Wars, p. 42.
} 
verdades morais que se encontram na base da clivagem entre os diferentes segmentos que atuam nesta contemporânea guerra de cultura. Segundo Hunter, esta clivagem é tão profunda que atravessa as antigas linhas de conflito, fazendo com que a distinção que durante tanto tempo dividiu os americanos - entre protestantes, católicos e judeus - seja hoje em dia praticamente irrelevante. As clivagens que atualmente demarcam os "territórios" (simbólicos) nesta guerra de cultura são definidas e analisadas por este sociólogo da cultura a partir de dois movimentos polares que ele qualifica como impulse toward orthodoxy ('impulso em direção à ortodoxia') e impulse toward progressivism ("impulso em direção à progressividade”). De acordo com Hunter, o sistema de crenças ou a visão de mundo em direção à ortodoxia define-se "pelo compromisso por parte de seus adeptos com uma autoridade externa, definível e transcendente, uma autoridade que é suficiente para todos os tempos". Por outro lado, no âmbito de uma postura progressista, "a autoridade moral tende a ser definida pelo o espírito da era moderna, um espírito do racionalismo e do subjetivismo. Deste ponto de vista, a verdade tende a ser vista como um processo, como uma realidade que está sempre se desdobrando. $\mathrm{O}$ que toda visão de mundo progressista tem em comum é a tendência a resimbolizar as crenças históricas de acordo com os pressupostos predominantes da vida contemporânea". ${ }^{42}$

Todavia, essas qualificações não nos devem levar ao erro de interpretar a guerra de cultura em curso apenas como uma expressão de diferentes opiniões ou atitudes, sobre esta ou aquela questão. Como destaca Hunter, esta guerra articula-se a partir de "concepções fundamentalmente diferentes de autoridade moral, sobre diferentes ideias e crenças sobre a verdade, o bem, as obrigações com o outro, a natureza da comunidade, e assim por diante". Além disso, ela se configura, em última instância, como "uma luta acerca da identidade nacional - sobre o significado da América, o que fomos no passado, o que somos agora e, talvez o mais importante, o que nós, como uma nação, aspiramos nos tornar no novo milênio", conclui o sociólogo. ${ }^{43}$

Com base nas análises propostas por James D. Hunter, podemos designar o atual movimento neo-ateísta como um dos atores deste novo realinhamento do conflito ou guerra de cultura que pode ser perfeitamente incluído no rol dos grupos e instituições políticas e culturais que se pautam por "impulsos em direção à progressividade”. ${ }^{44}$ Nesta perspectiva, podemos afirmar que presença

\footnotetext{
${ }^{42}$ HUNTER, James. Culture Wars, p. 44.

${ }^{43}$ HUNTER, James. Culture Wars, p. 49-50.

${ }^{44}$ Muito embora os atores neo-ateístas sejam incluídos aqui numa posição contrária à ortodoxia
} 
do neo-ateísmo neste cenário constitui uma contrapartida ao discurso moral fundado numa perspectiva bíblico-religiosa e às suas emulações políticas, tal como pode ser constatado nos próprios argumentos dos neo-ateístas.

Assim sendo, verificamos que o movimento neo-ateísta constitui-se a partir de um diferente sistema de entendimento moral a partir do qual opera sua própria constelação de valores, interesses e pressupostos. A perspectiva cultural neo-ateísta, com sua específica concepção de autoridade moral, de apreensão da realidade e do ordenamento das experiências, opõe-se justamente a uma moralidade de extração religiosa, em especial aquela fundamentalista que aceita a inerrância bíblica.

De fato, como já mencionado, Arthur Bradley e Andrew Tate indicam que o neo-ateísmo pode ser visto como uma resposta político-cultural ao ressurgimento do fundamentalismo protestante norte-americano, neste cenário de novo realinhamento de velhos antagonismos. Esses autores consideram ser o fundamentalismo cristão o principal antagonista do neo-ateísmo. Assim sendo, na avaliação deles,

De um lado, o fundamentalismo cristão professa sua fé na inerrância da Bíblia, na doutrina luterana da sola scriptura, na verdade literal da Gênesis e no primado da moralidade pessoal. Do outro lado, o neo-ateísmo oferece igualmente apenas uma leitura a-histórica e descontextualizada da Bíblia e do Alcorão, insistindo na falsidade literal da Gênesis e na imoralidade patente de um sistema de valores que se baseie numa "verdade" religiosa revelada. ${ }^{45}$

Como temos visto, o neo-ateísmo assume abertamente uma postura de oposição ao fundamentalismo em geral e ao fundamentalismo cristão norteamericano, em particular. Sam Harris, por exemplo, afirma no prefácio de sua obra Letter to a Christian Nation que "o propósito primário do livro é armar os secularistas de nossa sociedade, os quais acreditam que a religião deve ser mantida fora da política pública, contra os seus oponentes na direita cristãa" ${ }^{46}$

devido a suas posturas secularistas e, como a maioria dos secularistas, sua tendência seja mesmo "progressista", Hunter observa que nos EUA existem secularistas que eventualmente se deixam orientar por uma perspectiva ortodoxa ou conservadora. Isto ocorre, por exemplo, quando há um compromisso com a lei natural ou quando há uma "concepção elevada da natureza que serve como um equivalente funcional da autoridade moral externa e transcendente, reverenciada por sua contraparte religiosamente ortodoxa". HUNTER, James. Culture Wars, pp. 45-46.

${ }^{45}$ BRADLEY, Arthur \& TATE, Andrew. The New Atheist Novel, pp. 4-5

46 "The primary purpose of the book is to arm secularists in our society, who believe that religion should be kept out of public policy, against their opponents on the Christian Right". HARRIS, 
Enquanto Dawkins, ao afirmar que todas as religiões são igualmente "erradas", "estúpidas" e "perigosas", deixa claro que seu principal alvo é quase sempre o fundamentalismo. Assim sendo, em The God Delusion, ele afirma, por exemplo, que enquanto cientista ele é "hostil à religião fundamentalista porque ele debocha ativamente do empreendimento científico. [...] Ela subverte a ciência e mina o intelecto". ${ }^{47}$ Mas as diferenças não se limitam a tais questões. Os neo-ateistas criticam e recusam a legitimidade de toda e qualquer proposta de política pública fundamentada em postulados contidos em livros sagrados que, como sabemos, são a fonte da verdadeira autoridade moral para muitos segmentos religiosamente orientados. Consequentemente, só admitem a legitimidade de políticas consoantes com suas próprias bases de entendimento moral. Portanto, com base numa visão de mundo que seria objetiva e universal, isto é, com base também em uma "verdadeira autoridade moral", o movimento neo-ateísta propõe cursos de ação que, no entendimento de seus articuladores, seriam os únicos capazes de recompor as instituições sociopolíticas em uma perspectiva secularista renovada. ${ }^{48}$

Uma das principais estratégias do neo-ateísmo para fazer-se valer como a única cosmologia ou mesmo como uma ontologia plausível e coerente para o nosso tempo, consiste em atacar a própria fonte de autoridade moral do discurso religioso cristão. Sam Harris considera que "a ideia de que a Bíblia seja um perfeito guia para moralidade é simplesmente assustador, dado o conteúdo do livro" ${ }^{49}$ Em sintonia com esta proposição, ele afirma no seu livro The End of Faith que "a generalizada ideia segundo a qual a religião é de alguma forma a fonte das nossas mais profundas intuições éticas é um absurdo. Não mais adquirimos entendimento de que a crueldade é errada por meio das páginas da Bíblia, assim como não mais adquirimos o entendimento de que 'dois mais dois é igual a quatro’ por meio das páginas de um livro de matemática”. Para Harris há um fato que, na sua avaliação, é incontestável: nossas intuições morais tem sua origem em nossa própria condição biológica, natural. Este fato revela, por conseguinte, "que nossos esforços para fundamentar a ética em

Sam. Letter to a Christian Nation. New York: Vintage Books, 2006, p. viii.

${ }^{47}$ DAWKINS, Richard. Deus, um delírio, p. 292 [The God Delusion, p. 321].

${ }^{48}$ Dentre as ações adotas pelo movimento neo-ateísta em relação à influência sociopolítica do cristianismo nos EUA, encontra-se, por exemplo, a oposição massiva à inclusão da teoria do Design Inteligente no currículo escolar das escolas daquele país. Ver: FORREST, Barbara. Understanding the Intelligent Design Creationism Movement Washington D.C.:Centre for Inquiry, 2007. Ver também: SHANKS, Niall. God, the Devil and Darwin A Critique of Intelligent Design Theory. Oxford University Press, 2004.

${ }^{49}$ HARRIS, Sam. Carta a uma Nação Cristã, p. 25. 
concepções religiosas de 'dever moral' são equivocados". ${ }^{50}$

Outros neo-ateístas são bem mais diretos em suas considerações. Muito embora considere que "grande parte da Bíblia não é sistematicamente má, mas simplesmente bizarra", Richard Dawkins, por exemplo, declara que "infelizmente, é este mesmo volume bizarro que fanáticos religiosos sustentam como fonte infalível de nossa moral e de nossas normas de vida". ${ }^{51}$ Assim sendo, a moralidade moderna, de onde quer que ela venha, não deve vir da Bíblia. Chistopher Hitchens, por sua vez, vai ainda mais além. Ao declarar que "a religião não é apenas amoral, mas positivamente imoral", ele tem em mente não apenas o discurso cristão, bíblico, seja ele liberal, fundamentalista ou tão somente conservador. ${ }^{52}$ Ele pensa aqui em toda e qualquer forma de religiosidade, instituição, experiência ou discurso religioso. Assim procedendo, ele recusa qualquer possibilidade de pensar e aceitar o discurso religioso tout court como uma reserva de sentido válida para nossas sociedades seculares.

\section{Conclusão}

Ao longo e dentro dos limites deste artigo, nos confrontamos com os argumentos utilizados pelos neo-ateistas norte-americanos em defesa suas teses sobre a religião, a política, a moral e a ciência. Para a realização deste objetivo recorremos aos aportes teóricos e conceituais presentes em obras do filósofo françês Marcel Gauchet e do sociólogo James Davison Hunter. Assim procedendo, chegamos à conclusão que o movimento neo-ateísta que emerge no início deste milênio possui algumas características peculiares, as quais devem ser sublinhadas.

Em primeiro lugar, vale destacar, mais uma vez, o fato de que este movimento vem à luz em contraposição ao ressurgimento político-cultural do fundamentalismo protestante e à emergência da nova direita cristã nos Estados Unidos, nas últimas décadas do século passado. Este processo resultou no redirecionamento de amplos setores do evangelismo do sul dos EUA em

\footnotetext{
50 "The pervasive idea that religion is somehow the source of our deepest ethical intuitions is absurd. We no more get our sense that cruelty is wrong from the pages of the Bible than we get our sense that two plus two equals four from the pages of textbook on mathematics. [...] The fact that our ethical intuitions have their roots in biology reveals that our efforts to ground ethics in religious conception of "moral duty" are misguided". HARRIS, Sam. The End of Faith, pp. 171-172. [A Morte da Fé, p.187-188]

${ }^{51}$ DAWKINS, Richard. Deus, um delírio, p. 246.

${ }^{52}$ HITCHENS, Christopher. Deus não é grande, p. 189.
} 
direção a uma efetiva participação político-partidária, algo inédito no contexto evangélico deste país, reforçado significativamente após 11 de setembro de 2001. É neste cenário que emerge e se consolida o processo que Oran Smith chamou, em 2000, de "ascenção do republicanismo batista". ${ }^{33}$ Assim sendo, contrariamente aos ateísmos anteriores, é na sua relação com este contexto de partidarização do evangelismo norte-americano e de introdução explícita do vocabulário moral-religioso no discurso e nas mediações político-partidárias tradicionais, que o movimento neo-ateísta norte-americano precisa ser considerado. Todavia, dado que este movimento possui um discurso éticopolítico cujas estruturas discursivas assemelham-se às do fundamentalismo cristão, entendemos que ele mesmo pode ser considerado uma espécie de fundamentalismo, como já sugerimos.

Assim sendo, devemos considerar, em segundo lugar e em consonância com as análises de Albert Mohler, que o neo-ateísmo não é somente uma reafirmação do ateísmo - o antigo ateísmo com nova roupagem. Na realidade, estes "novos ateístas são, à sua própria maneira, evangelistas em sua intenção e ambiciosos em sua esperança". ${ }^{44}$ De fato, lendo os neo-ateistas é possível perceber que o movimento do qual fazem parte quer ser um amplo movimento social, organizado com vistas à implementação político-cultural de suas próprias propostas e de uma perspectiva secular renovada. Convêm lembrar, todavia, que deste ponto de vista a proposta neo-ateista mais radical de eliminação ou erradicação do discurso religioso de espaço público ou mesmo privado, implica em investir sobre duas instituições típicas, condições sine qua non da sociedade norte-americana contemporânea: investir sobre o pluralismo, pela via de sua redução e sobre a dimensão multireligiosa da esfera pública, pela via de sua desestruturação. Mas, será isto efetivamente possível?

Finalmente, muito embora este artigo tome por base os conflitos e debates travados no âmbito da cultura e do espaço público norte-americano, não acreditamos estar tratando de um caso isolado, remoto e sem implicações externas. Pelo contrário, consideramos este cenário norte-americano de guerra cultural uma variante singular de um processo mais amplo que é o da crise dos fundamentos espirituais da democracia. Na realidade, este cenário e o realinhamento de antigos conflitos culturais que ele comporta, é uma variante da modificação maior na autocompreensão do próprio Estado

\footnotetext{
${ }^{53}$ Smith, Oran, The rise of baptist republicanism, Nova York: Ed. University of New York Press, 2000 .

${ }^{54}$ MOHLER Jr., R. Albert. Ateísmo remix, p. 16.
} 
secular: o "fundamentalismo secularista" da democracia política perde paulatinamente sentido. ${ }^{55}$ Sabemos que o Estado de direito tornou-se sinônimo de democracia e, portanto, vem garantindo a salvaguarda das liberdades privadas e, simultaneamente, o respeito aos procedimentos políticos e jurídicos que regulavam a expressão pública dessas mesmas liberdades. Nesse sentido, muito embora a democracia se caracterize por ampliar o lugar e a função das liberdades individuais, equivalendo, no plano politico, a uma sociedade onde a participação politica dos indivíduos dá-se por escolha livre e voluntária, a garantia final destas escolhas tem sido dada pelo próprio Estado enquanto expressão da unidade coletiva. Concebido como "árbitro imparcial", como potência pública caracterizada pela neutralidade moral ou espiritual, ou seja, como guardião neutro da coexistência e da livre expressão das diferentes crenças e conviç̧ões, religiosas ou não, o Estado democrático moderno foi coetâneo da progressiva alocação da religião no domínio das escolhas privadas. Nesse contexto, a religião passou a ser considerada um conjunto de crenças e doutrinas restritas a área da vida privada, enquanto que a vida política democrática e as instituições públicas e estatais foram concebidos como os exclusivos portadores de sentido universal para o estar-junto coletivo e para os próprios indivíduos. Assim sendo, o Estado Nacional constituiu-se como o fator por excelência de identificação coletiva e de estabilidade política. Tornou-se, no final das contas, a única instituição supostamente capaz de fornecer uma via segura para o acesso de todos os indivíduos e povos - com suas diferentes culturas e religiões - à modernidade, ou seja, à liberdade individual, à estabilidade política e ao desenvolvimento econômico.

É o processo mesmo de radicalização deste princípio de neutralidade moral ou espiritual da potência pública que provoca uma reversão das expectativas secularizantes. $\mathrm{O}$ fato é que neutralidade radical da potência pública não impede que no espaço público tomem corpo ideais substanciais de "bem", de "felicidade" e de "fim último", dentro outros. Assim sendo, a democracia no ponto extremo de sua atual e completa neutralidade axiológica culmina por recolocar a religião e as comunidades religiosas na proximidade da potência

\footnotetext{
${ }^{55}$ Entendemos por "fundamentalismo secularista" a concepção segundo a qual o Estado moderno possui, enquanto potência pública, uma "superioridade metafísica" que deve ser mantida a todo custo e que se caracteriza pela absoluta neutralidade moral e espiritual com relação a questões que dizem respeito aos "fins últimos" da existência humana. Este "fundamentalismo" foi (e continua sendo) o responsável pelo deslocamento do senso de sacralidade atribuído a Deus ou ao Rei para a Nação e a Lei.
} 
pública. Não tanto na forma de instituição religiosa, mas na forma de sistemas e reservas de sentido e de concepções válidas sobre questões "perenes", que sua neutralidade mesma não lhe permite fornecer, deixando subentender com isto que a que a vida política por si só pode não ser mais portadora de sentido universalmente válido para o estar-junto coletivo.

Como vimos, desde 1970 assistimos o ressurgimento de movimentos fundamentalistas que intensificam o apelo por "regras e "normas", respondendo à referida crise dos fundamentos da democracia com demandas por regulamentações normativo-coercitivas na prática política e com a instalação do que muitos chamam de "ordem moral" ou "ética", na tentativa de ancorar a ação política em novos absolutos. Esta dinâmica, por sua vez, assinala a possibilidade de uma desconstrução progressiva da unidade política coletiva, ou, o que é o mesmo, da nação, mantida ainda pelo Estado de direito. Queremos argumentar que em tal contexto certas religiões - como as evangélicas e as neopentecostais, por exemplo - que poderão efetivamente vir a ser "religiões globalizadas" ou transnacionais, poderão vir a ser também politicamente deconstrutivas. Operosas no esforço de fazer ressurgir o ponto de vista normativo (associado, desta feita, a uma prescritividade de cunho moral-religioso) como fundamento da ação política, elas parecem consubstanciar e desempenhar com mais eficácia a função de criação de novos sentidos para o estar-junto coletivo (a partir de uma simbólica explicitamente religiosa). Assim procedendo, culminam por repropor a perspectiva teológico-política como fundamento da unidade política coletiva. Esta unidade, como já indicamos, é algo que a democracia requer para sua própria sobrevivência. No entanto, tudo indica que a que a neutralidade axiológica radical do Estado democrático parece não ser mais capaz de produzí-la a contento. No nosso entendimento, este processo não é exclusivo dos EUA, muito embora encontra-se em fase avançada neste país e, portanto, precisa ser devidamente compreendido.

\section{Referências Bibliográficas}

BRADlEY, A. \& TATE, A. The New Atheist Novel. Philosophy, Fiction and Polemic after 9/11.London/New York: Continuum International Publishing Group, 2010.

DAWNKINS, Richard. The Blind Watchmaker: Why the Evidence of Evolution 
Reveals a Universe without Design, New York: W. W. Norton, 1986. Deus, um delírio. São Paulo: Companhia das Letras, 2007.

DEMBSKI, William A. The End of Christianity. Tennesse: B\&H Publishing Group, 2010.

DENNETT, Daniel. Darwin's dangerous Idea: evolution and the meanings of life. New York:Simon \& Schuster, 1995.

Breaking the Spell: Religion as a Natural Phenomenon. New York: Viking, 2006.

EUVÉ, François. Darwin et le christianisme, vrais et faux débats. Paris: Buchet Chastel, 2009.

FERRY, Luc \& GAUCHET, Marcel, Le religieux aprés la religion, Paris: Ed. Grasset et Fasquelle, 2004.

FORREST, Barbara. Understanding the Intelligent Design Creationism Movement Washington D.C.:Centre for Inquiry, 2007.

GAUCHET, Marcel. El desencantamiento del mundo: uma história política de la religión. Trad. Esteban Molina. Madri: Trotta, 2005.

Grasset, 2004.

Le Religieux après la religion (avec Luc Ferry). Paris:

Un Monde Désenchanté? Paris : Les Éditions de l'Atelier/Éditions Ouvrières, 2004.

GOLDMAN, Emma. The Philosphy of Atheism. In: HITCHENS, Christopher. The Portable Atheist:essential readings for the nonbeliever. Philadelphia: Da Capo Press, 2007.

GOLDBERG, Michelle. Kingdom Coming: The Rise of Christian Nationalism. New York: W. W. Norton, 2006.

GORDON, Flávio. A Cidade dos Brights: Religião, Política e Ciência no MovimentoNeo-Ateísta. Rio de Janeiro: UFRJ, 2010.

GOULD, Stephen Jay. Pilares do Tempo: ciência e religião na plenitude da 
vida. Rio de Janeiro: Rocco, 2002.

HARRIS, Sam. The End of Faith: Religion, Terror, and the Future of Reason. New York:W.W. Norton, 2005.

. A Morte da Fé: religião, terror e o futuro da razão. São Paulo: Companhia das Letras, 2009. . Letter to a Christian Nation. New York: Vintage Books, 2006. . Carta a uma Nação Cristã. São Paulo: Companhia das Letras, 2007.

HEELAS, Paul \& MARTIN, David. Religion, modernity, and postmodernity. Massachusetts USA Editora: Blackweel Publishers. 1999.

HITCHENS, Christopher. Deus não é Grande: como a religião envenena tudo. Rio de Janeiro: Ediouro, 2007.

HUNTER, James Davison. Culture wars: the struggle to define America. New York: Basic Books,1991.

JOHNSON, Phillip E. Darwin no banco dos réus. São Paulo:Cultura Cristã, 2008.

LENNOX, John. God's Undertaker: Has Science Buried God? Lion Hudson, Oxford, 2007.

MAYRS, Ernst. Darwin's Influence on Modern Thought, Scientific American (julho de 2000)

MOHLER JR., R. Albert. Ateísmo remix: um confronto cristão aos novos ateístas. São José dos Campos: Ed. Fiel, 2009.

NEIMAN, Susan, $O$ mal no pensamento moderno. Uma história alternativa da filosofia. Rio de Janeiro: Ed. DIFEL, 2003.

ROBBINS, J. W. \& MAGEE, N. The sleeping giant has awoken: the new politics of religion in theunited states. New York: The Continuum International Publishing Group, 2008.

SHANKS, Niall. God, the Devil and Darwin A Critique of Intelligent Design Theory. Oxford: Oxford University Press, 2004. 
SMITH, Oran, The rise of baptist republicanism. Nova York: Ed. University of New York Press, 2000.

STAHLBERG, Ben. Theocratic America? Christianity and the Structure of Political Discourse.

In: ROBBINS, J. and MAGEE, N. The Sleeping Giant has Awoken: The new politics of religion in the United States. New York: The Continuum International Publishing Group,2008.

\section{Wilmar do Valle Barbosa}

Pós-Doutor em Filosofia pela Universidade de Pisa. Professor Associado do Programa de Pós-Graduação em Ciência da Religião do Instituto de Ciências Humanas da UFJF.

E-mail: wilmarvalle@uol.com.br

Roney de Seixas Andrade Doutorando no curso de Pós-Graduação em Ciência da Religião do Instituto de Ciências Humanas da UFJF. Bolsista da CAPES. E-mail: roneyseixas@yahoo.com.br

Recebido em: 12/11/2012 Aprovado em: 03/02/13 